\title{
Challenges in Knowledge Management for Structuring Systems
}

\author{
Vincent Cheutet ${ }^{*}$, Marc Zolghadri, Florent Couffin, Patrice Leclaire, \\ Roberta Costa Affonso, and Caroline Bourcier \\ LISMMA/SUPMECA, \\ 3 rue Fernand Hainaut, \\ 93400 Saint-Ouen, France \\ vincent. cheutetasupmeca.fr
}

\begin{abstract}
Structuring Systems can be defined as systems, designed, installed, used and maintained within their operational environment for an extremely long duration, answering to the fundamental needs of the society. Examples of such systems are water systems, transport or electricity network. Due to their nature, these systems are characterized to be highly complex, according to the general system theory. In this context, the classical Knowledge Management (KM) approaches are not suited, due to the nature and origins of some data, information and knowledge, the complexity of partner networks that are interacting around the systems, the evolution history of such systems, etc. In this article, we present the main challenges for KM in Structuring Systems, especially in terms of knowledge traceability and heritage from one hand, and knowledge preservation at another one.
\end{abstract}

Keywords :tructuring systems, knowledge management, traceability, heritage.

\section{$1 \quad$ Introduction}

In recent years, companies showed a growing interest in Data, Information and Knowledge Management (DIKM) to ensure their competitiveness. (Tsuchiya, 1993) introduces a distinction between datum, information and knowledge: "Although terms "datum", "information" and "knowledge" are often used interchangeably, there exists a clear distinction among them. When datum is sense-given through interpretative framework, it becomes information, and when information is sense-read through interpretative framework, it becomes knowledge". In companies and research literature, DIKM is classically separated in two main domains: on one hand, data and information management realised by information system, and on the other, knowledge management.

Various papers have contributed to improve comprehension of the specific characteristics of knowledge (Bernard and Tichkiewitch, 2008). The concept of Knowledge Capitalization appeared since 1990 in an objective of preserving and enhancing the

\footnotetext{
* Corresponding author.
} 
know-how acquired in an organization. It can be described by the model proposed by (Grundstein 2012), composed of five facets (Fig. 1): locate the knowledge, preserve the knowledge, enhance the knowledge, actualize the knowledge, and manage the interactions between the 4 preceding facets.

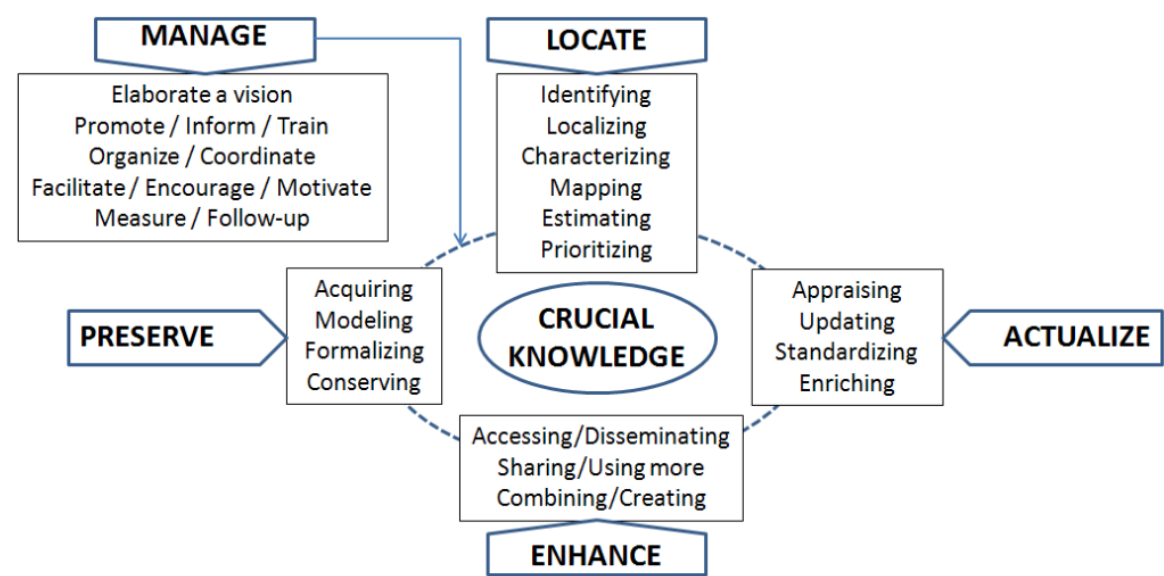

Fig. 1. The problem of knowledge capitalization in company (Grundstein, 2012)

Knowledge Management (KM) is defined as the management of activities and processes aiming at increasing the creation and usage of knowledge inside an organisation. The valorisation of knowledge satisfies an economic issue at stake for both society (UNESCO, 2005) as well as companies. As a consequence, a large literature exists on different domains. Nevertheless, most of KM works have been developed for companies specialised in design, production and control of industrial products or complex systems. Structuring Systems (Zolghadri et al., 2013), like water systems or transport networks, are systems that currently require a new vision of knowledge management suited to their characteristics.

The article is constructed as follow. After a brief state-of-art in Section 2 on main research contributions in KM, Section 3 defines and characterizes Structuring Systems. Based on these two analyses, Section 4 enlightens the main challenges in KM for Structuring Systems.

\section{Knowledge Management State-of-the-Art}

To satisfy the issues at stake in the valorisation of knowledge, there are two main approach strategies: approaches focussing on the reification of knowledge and those focussing on individuals as holders of knowledge. (McMahon et al., 2004) summarises the various terms relative to these approaches as: "commodity view", "codification" and "object view" for the first and "community view", "personalisation" and "process view" for the second. 
Personalisation approaches cover the various knowledge transformation mechanisms as applied within an individual or between individuals when they are freely expressed and lead to solutions oriented towards practices communities (Amin and Roberts, 2008) as well as CSCW-type (Computer-Supported Collaborative Work) tools (Lewkowicz and Zacklad, 2001).

Codification approaches cover the elicitation of knowledge in a controllable form beyond the actual individual and are, for the most part, based on information and communication technology (Chen and Huang, 2012). This explicit knowledge desynchronised from the interpretative framework of individuals then takes on a dual information/knowledge status. The simple documents, codified in line with the interpretative framework of the individuals who will read them, will be a source of knowledge for them similar to that of the people who wrote these documents. In this case, it becomes possible to consider these documents as knowledge. Otherwise, it will be information source of knowledge. Moreover, the information embedded in expert systems constitutes the intrinsic knowledge of these systems inasmuch as they are able to use it to reason, via their own interpretative patterns.

In his analysis of the literature produced between 1995 and 2002 on the technology and applications covered by knowledge management, Liao (2003) identified seven technical areas, which (Louis-Sidney et al., 2012) proposes to combine as follows:

- framework(1) and modelling (2),

- artificial intelligence (KBS(3) and expert systems (4)),

- databases (5), data mining(6) and information and communication technology (ICT) (7) (e.g. the Internet, Extranets and wireless web..).

The technical fields covering the tools made directly available to product designers to carry out their redesign activities, supporting the codified knowledge, are those of artificial intelligence for a very formal approach, and databases, data mining and ICT where less formal codification approaches are used.

(Chandrasegaran et al., 2013) reviews current research works in Knowledge representation and capture in product design and concludes by this sentence: "Although much progress has been made as outlined in the current paper, we are yet to see wide spread use of knowledge-aided systems in the industry". (Verhagen et al., 2012) reviews current research works in Knowledge-Based Engineering, and points out in particular the needs in improving methodologies to support KBE development project, and in developing knowledge traceability.

Moreover none of the research contributions elicited in these two articles tackles the specific context of Structuring Systems.

\section{$3 \quad$ Structuring Systems}

In this paper, Structuring Systems are defined as systems, designed, installed, used and maintained within its operational environment for an extremely long duration, answering to the fundamental needs of the society (Zolghadri et al., 2013).

As a special type of systems, a Structuring System shares with general systems some fundamental properties such as: 
- it is composed of subsystems,

- these subsystems are interconnected,

- they have dependencies with their environment within which they have various exchanges. This environment is composed not only of other structuring systems but other kind of systems.

Moreover, compared with other types of systems, the Structuring Systems have a very long utilization duration, disproportionately higher than the other phases. To take concrete examples of these systems, we can name the water supply systems, energy networks (electricity), transport networks (road, rail, inland waterways), the sites of highly hazardous waste and / or toxic (nuclear, chemical, etc.).

Let us now qualify these services thanks to three criteria: (1) Number of users, (2) Usage frequency, and (3) Usage duration. A product or system provides its services to either one individual customer or a more or less large group of customers. The frequency of usage and also the duration of the service usage by customers could vary from one kind of service to another. These three criteria allow to structure the space of the services offered by a product or a system (Fig. 2).

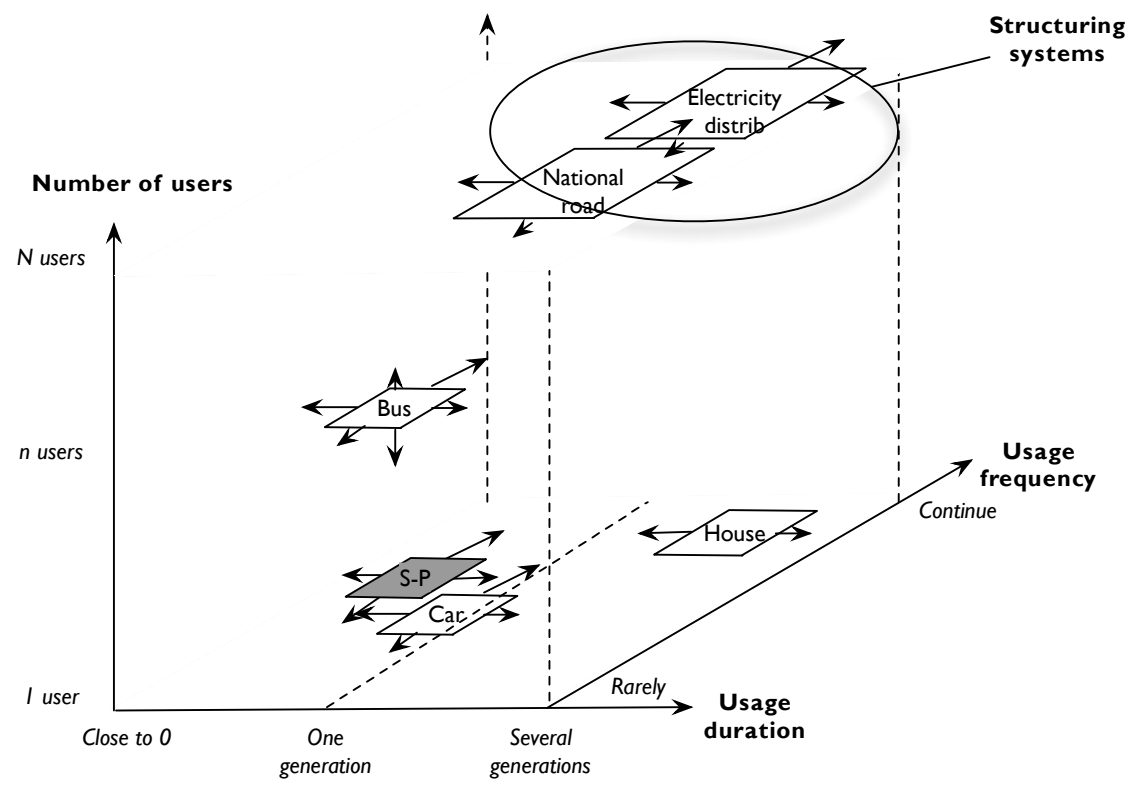

Fig. 2. The usage space of a product or a system

According to this usage space, we suggest a very first sub-space where the structuring systems are gathered and a very first definition of such systems is the following: "A structuring system is as a complex system which offers its services for a very long period of time covering more than one generation of human being. A structuring system is a heritage of its users". 
Other dimensions of the structuring systems' characterisation reveal some properties that allow to understand them in a better way:

- these systems are made of a large number of inter-connected sub-systems forming a complex network,

- mainly they correspond to the public utility organizations, and their highest-level decision-makers are the public authorities that are accountable of their decisions to citizens,

- they are firmly connected to other Structuring Systems but use a myriad of products (computers, cars, etc.),

- their operation phase duration is much longer than any other phase of their lifecycle,

- they are in perpetual evolution and one can hardly define their end-of-life,

- they are continuously partially re-designed and refurbished, and continuously maintained.

We can qualify these systems as structuring because they have such deep influences on the society, economy and their eco-systems that they become the main drivers of their evolution (Berion et al., 2007). They play a crucial role in the organisation of actors and their relationships. This is to say that structuring systems structure themselves, eco-systems in which they are implemented but also other systems with which they are connected. The structuring systems express, control and drive the "heavy trends" of the eco-system. These systems are the concretisation of the main political and societal inspiration of a country that goes much further than other kind of design decisions.

From the previous definition, Structuring Systems have several principles that are typical of such systems:

- continuous answer to evolving needs: since consumers' needs evolve not only according to the general evolution of science and technologies but also thanks to the evolution of their own awareness (see (Tillman, 2001) for the water needs evolution for instance), Structuring Systems have the obligation of service continuity and they are so reconfigured or changed partially to cope with the evolving needs,

- incipience-germination-coalescence: the existing Structuring Systems have been and are still obtained thanks to this iterative threefold process (Fig.3),

- functional, structural and technological continuity: due to non service break and long-life principles, these systems are inherited and partial evolution of such systems have to ensure continuity with their history, at the three levels,

- durable impacts on and from the environment: some impacts can be tangible in the short term (population movement after the construction of a new bridge) while others may be observed slowly, e.g. the change of the industrial landscape after the construction of transportation infrastructure (Berion et al., 2007). 


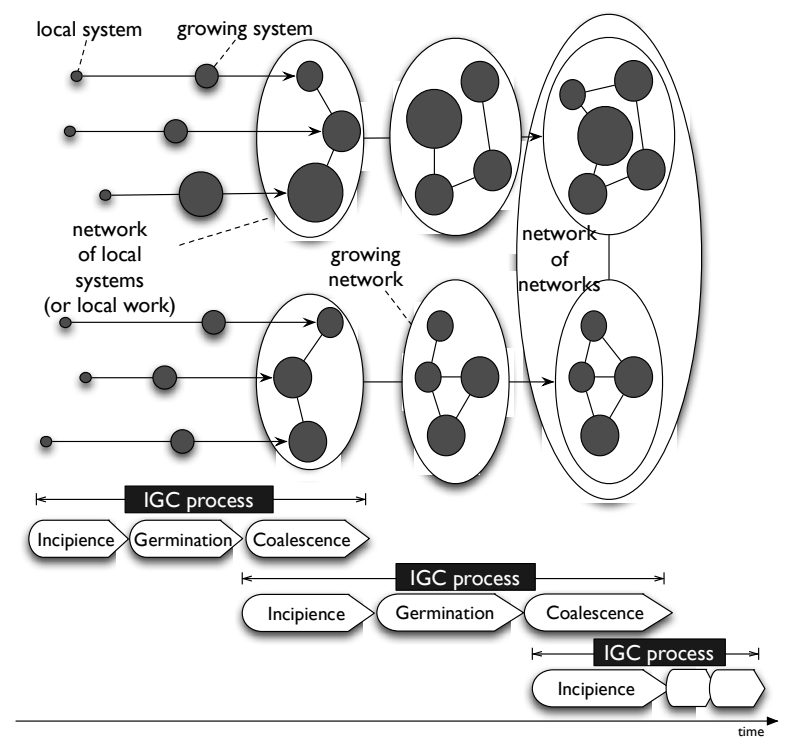

Fig. 3. Iterative process for Structuring Systems: incipience-germination-coalescence

Structuring Systems cover durable needs of users. In this case, the local and national public authorities are the main decision-makers and strategy definers. Nevertheless, private actors are often involved in almost all of the lifecycle's phases. Public and private financing organisations are also those partners that allow a structuring system to be launched, used and maintained. We can model the connections among all these actors by the model represented in Fig. 4.

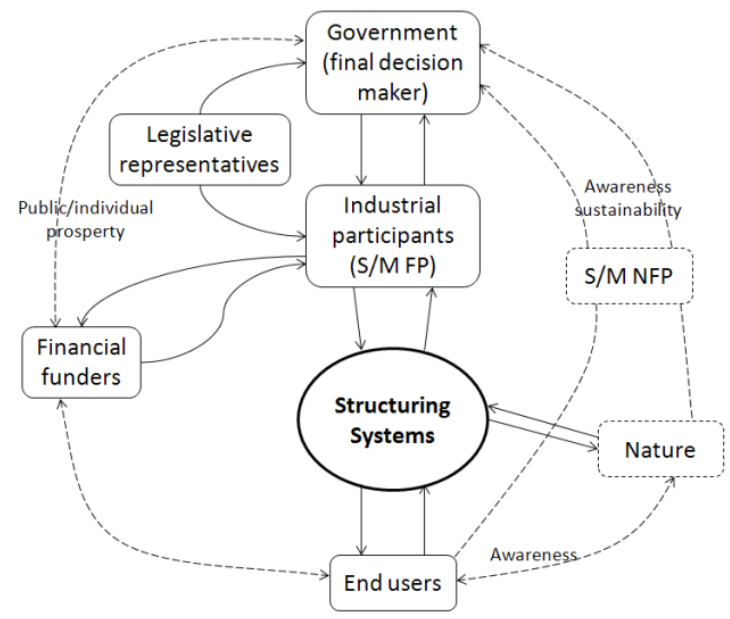

Fig. 4. Influences among stakeholders and a Structuring System 
KM approaches have been partially deployed in several Structuring Systems, specifically at each system. The major contributions are related to knowledge-based engineering, with the development of knowledge-based systems to support decision processes associated to these structuring systems, potentially by simulating human expertise during the problem solving process, either for the water domain (Wukovits et al., 2003), (Chau, 2007), (Garrido-Baserba et al., 2012), or the urban planning one (Rubenstein-Montano, 2000). In particular, (Davis, 2000) details a specification that identifies the types of data, knowledge, and internal and external factors likely to be of relevance in a full decision-support tool (Fig. 5), proving the diversity of partners implied in the decision process and the complexity of knowledge management required to support such process.

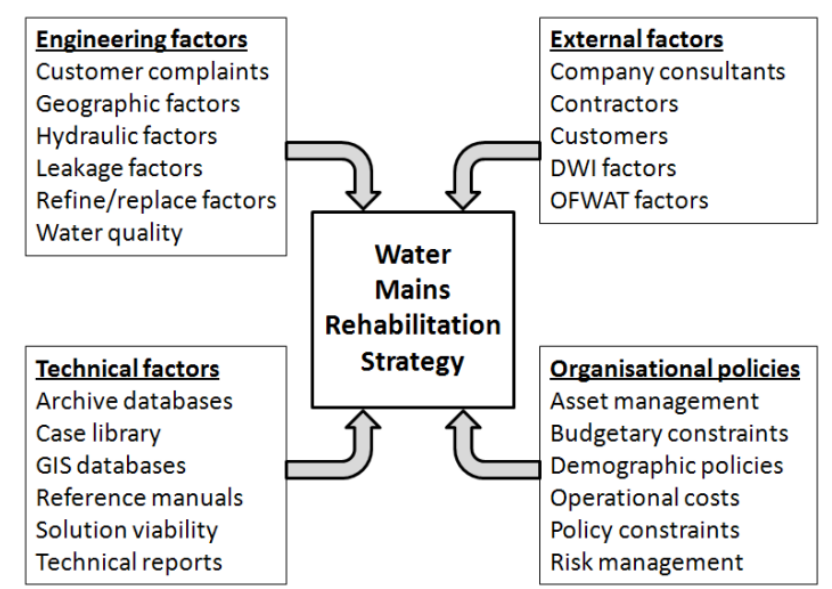

Fig. 5. Influences to be captured in a complete decision-support tool (Davis, 2000)

\section{Challenges in KM for Structuring Systems}

The previous sections have enlightened two characteristics of Structuring Systems: they are continuously evolving, and innovation is an important aspect. These two dimensions are deeply connected to the knowledge existing on them.

Nevertheless, several issues attached to Structuring Systems make KM more complex and current approaches in this domain are not suited. If the model in five facets can still be used, each facet should be re-imagined in the context of Structuring Systems.

\subsection{Locate Knowledge for Structuring Systems}

Structuring Systems, due to their nature, are inherited from a long history, and their architecture is so the result of past decisions that may be lost at that time. (Kujinga and Jonker, 2006) illustrates on the example of water governance transformation in Zimbabwe how the knowledge diffusion process is as non-easy and non-intuitive as expected. As a consequence, locate knowledge generated and used during this history is a complex task, with two main dimensions. 
The first dimension is related to the large scale of actors that may contribute and/or interact with structuring systems. In this case, specific knowledge capture approaches are needed, for instance by analyzing either knowledge co-production between different partners (Hordijk and Baud, 2006), (Edelenbos et al., 2011), or cognitive biases from human expertise in the domain (Scholten et al., 2012), (Taylor and de Loë, 2012).

The second dimension is more associated to time scale and especially the inheritance of such systems. In this case, knowledge may have disappeared and locate such knowledge is more associated to the archaeology discipline (Bernard \& Proust, 2013). To help this archaeology task, even if a methodology to support such process is still required, several approaches and tools may be of prior interest:

- extraction of information and knowledge from ancient texts, like the approaches proposed by (Gomez and Segami, 2007) or by (Buitelaar et al., 2008),

- Reverse Engineering, where the objective is not only to reconstruct a complete model of a piece, but also to capture the initial design intent (Huang and Tai, 2000), (Durupt et al., 2010) and reconstruct knowledge and competencies implemented at the origin.

\subsection{Preserve Knowledge for Structuring Systems}

Since their usage time is far from being finished, to preserve such knowledge requires specific preservation techniques, called Long Term Digital Preservation (NLA, 2003), with the mean of keeping digital information so that the same information can be used at some point in the future in spite of obsolescence of everything involved: hardware, software, processes, format, people, etc. Such LTDP approach has contributed to the definition of the OAIS (Open Archival Information System) Standard (ISO 14721:2012).

In the domain of product development (and especially aeronautics), several approaches have been proposed for digital preservation of data and information attached, like the LOTAR project (LOTAR, 2013).

Nevertheless, the main interest of such projects is until now to preserve only data or information attached to the products, like digital geometric data (Regli et al., 2011). In our case, preserving technical and organisational knowledge, especially the one attached to any decision process that may be crucial in 150 years for instance, needs further research.

\subsection{Enhance and Actualise Knowledge for Structuring Systems}

As previously said, Structuring Systems are characterized by a large diversity of stakeholders that are contributing and/or interacting all over the usage time of such systems. Decisions and so knowledge are distributed in organisations that can be considered as short-lived ones compared to the service non-end time of Structuring Systems.

A change of paradigm is so needed for Knowledge Management and the facets "Enhance" and "Actualise" in particular, to attached knowledge not to the organisation that creates knowledge but to the systems by itself. 


\section{References}

Amin, A., Roberts, J.: Knowing in action: Beyond communities of practice. Research Policy 37(2), 353-369 (2008)

Berion, P.: The construction of a major transport infrastructure and its initial territorial impacts; the case of the A39 motorway between Dole and Bourg-en-Bresse. Géocarrefour 77(1), 720 (2002)

Bernard, A., Proust, C.: Ancient Scientific Sources and Teaching Contexts: Problems and Perspectives. Springer (2013)

Bernard, A., Tichkiewitch, S.: Methods and tools for effective knowledge life-cycle management. Springer (2008)

Buitelaar, P., Cimiano, P., Frank, A., Hartung, M., Racioppa, S.: Ontology-based information extraction and integration from heterogeneous data sources. International Journal of HumanComputer Studies 66(11), 759-788 (2008)

Chandrasegaran, S.K., Ramani, K., Sriram, R.D., Horváth, I., Bernard, A., Harik, R.F., Gao, W.: The evolution, challenges, and future of knowledge representation in product design systems. Computer-Aided Design 45(2), 204-228 (2013)

Chau, K.W.: An ontology-based knowledge management system for flow and water quality modelling. Advances in Engineering Software 38(3), 172-181 (2007)

Chen, Y.Y., Huang, H.L.: Knowledge management fit and its implications for business performance: A profile deviation analysis. Knowledge-Based Systems 27, 262-270 (2012)

Committee on National Security Systems, National information assurance glossary (2010), http: / /www. cnss.gov/Assets/pdf/cnssi_4009.pdf (accessed January 15, 2013)

Davis, D.: Agent-based decision-support framework for water supply infrastructure rehabilitation and development. Computers, Environment and Urban Systems 24(3), 173-190 (2000)

Durupt, A., Remy, S., Ducellier, G.: Knowledge Based Reverse Engineering-An Approach for Reverse Engineering of a Mechanical Part. Journal of Computing and Information Science in Engineering 10(4) (2010)

Edelenbos, J., van Buuren, A., van Schie, N.: Co-producing knowledge: joint knowledge production between experts, bureaucrats and stakeholders in Dutch water management projects. Environmental Science \& Policy 14(6), 675-684 (2011)

Garrido-Baserba, M., Reif, R., Hernández, F., Poch, M.: Implementation of a knowledge-based methodology in a decision support system for the design of suitable wastewater treatment process flow diagrams. Journal of Environmental Management 112, 384-391 (2012)

Gomez, F., Segami, C.: Semantic interpretation and knowledge extraction. Knowledge-Based Systems 20(1), 51-60 (2007)

Grundstein, M.: Three postulates that change knowledge management paradigm. In: Hou, H.-T. (ed.) New Research on Knowledge Management Models and Methods, ch. 1 (2012)

Hordijk, M., Baud, I.: The role of research and knowledge generation in collective action and urban governance: How can researchers act as catalysts? Habitat International 30(3), 668689 (2006)

Huang, M.C., Tai, C.C.: The pre-processing of data points for curve fitting in reverse engineering. The International Journal of Advanced Manufacturing Technology 16, 635-642 (2000)

ISO 14721:2012 Space data and information transfer systems - Open archival information system (OAIS) - Reference model 
Kujinga, K., Jonker, L.: An analysis of stakeholder knowledge about water governance transformation in Zimbabwe. Physics and Chemistry of the Earth 31(15-16), 690-698 (2006)

Lewkowicz, M., Zacklad, M.: Une nouvelle forme de gestion des connaissances basée sur la structuration des intéractions collectives. In: Zacklad, M., Grundstein, M. (eds.) Ingénierie et Capitalisation des Connaissances, ch. 3, pp. 49-64. Hermès Sciences Publication (2001)

Liao, S.H.: Knowledge management technologies and applications-literature review from 1995 to 2002. Expert Systems with Applications 25(2), 155-164 (2003)

LOTAR, LOng Term Archiving and Retrieval (2013), http: / /www. lotar-international .org/

Louis-Sidney, L., Cheutet, V., Lamouri, S., Puron, O., Mezza, A.: A conceptual model for the implementation of IKOES in automotive industry. Engineering Applications of Artificial Intelligence 5(5), 1090-1101 (2012)

McMahon, C., Lowe, A., Culley, S.: Knowledge management in engineering design: personalization and codification. Journal of Engineering Design 15(4), 307-325 (2004)

National Library of Australia, Guidelines for the Preservation of Digital Heritage. UNESCO (2003)

Regli, W.C., Kopena, J.B., Grauer, M.: On the long-term retention of geometry-centric digital engineering artifacts. Computer-Aided Design 43(7), 820-837 (2011)

Rubenstein-Montano, B.: A survey of knowledge-based information systems for urban planning: moving towards knowledge management. Computers, Environment and Urban Systems 24(3), 155-172 (2000)

Scholten, L., Scheidegger, A., Reichert, P., Maurer, M.: Combining expert knowledge and local data for improved service life modeling of water supply networks. Environmental Modelling \& Software (2012), doi:10.1016/j.envsoft.2012.11.013

Taylor, B., de Loë, R.C.: Conceptualizations of local knowledge in collaborative environmental governance. Geoforum 43(6), 1207-1217 (2012)

Tillman, D.: Stakeholder analysis in water supply systems. Swiss Federal Institute of Technology, $\mathrm{PhD}(2001)$

Tsuchiya, S.: Improving Knowledge Creation Ability through Organizational Learning. In: Proceedings of ISMICK, Compiègne, France (1993)

UNESCO, Towards Knowledge Societies (2005), http://www. unesco.org/new/en/ unesco/resources/online-materials/publications / unesdoc-database/ (accessed January 15, 2013)

Verhagen, W.J.C., Bermell-Garcia, P., van Dijk, R.E.C., Curran, R.: A critical review of Knowledge-Based Engineering: An identification of research challenges. Advanced Engineering Informatics 26(1), 5-15 (2012)

Wukovits, W., Harasek, M., Friedl, A.: A knowledge based system to support the process selection during waste water treatment. Resources, Conservation and Recycling 37(3), 205-215 (2003)

Zolghadri, M., Couffin, F., Cheutet, V., Bourcier, C., Costa Affonso, R., Leclaire, P.: Structuring Systems. LISMMA technical report (2013) 